\title{
Temperature-dependent kinetics of aluminum leaching from peat clay
}

\author{
Agus Mirwan ${ }^{a},{ }^{*}$, Susianto Susianto ${ }^{b}$, Ali Altway ${ }^{b}$, Renanto Handogo ${ }^{\text {b }}$ \\ a Department of Chemical Engineering, Faculty of Engineering, Lambung Mangkurat University, Banjarbaru 70714, Indonesia \\ b Department of Chemical Engineering, Faculty of Industrial Technology, Institut Teknologi Sepuluh Nopember, Surabaya 60111, Indonesia
}

* Corresponding author: agusmirwan@ulm.ac.id

\section{Article history}

Received 8 March 2019

Revised 9 October 2019

Accepted 20 November 2019

Published Online 15 April 2020

\section{Graphical abstract}

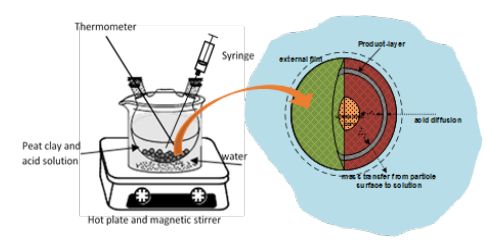

\begin{abstract}
The leaching kinetics of aluminum from peat clay using $4 \mathrm{M} \mathrm{HCl}$ at dissimilar leaching temperatures $\left(30-90{ }^{\circ} \mathrm{C}\right.$ ) was investigated. The maximum of aluminum recovery was $91.27 \%$ after $60 \mathrm{~min}$ of leaching in agitated Pyrex reactor at $90^{\circ} \mathrm{C}$. The model involved the concept of shrinking core in order to describe aluminum that is located inside the core solid particle of peat clay that shrinks as the extracted solute, and it assumed the unchanged particle structure, a first-order leaching kinetics mechanism and a linear equilibrium at the interface of solid-liquid. The proposed model was corresponding to fit experimental data and to simulate the aluminum leaching from peat clay with four fitting parameters of temperature. The result was confirmed with the mass transfer coefficient $\left(k_{c}\right.$, $\mathrm{cm} / \mathrm{s})$, diffusion coefficient $\left(D_{e}, \mathrm{~cm}^{2} / \mathrm{s}\right)$, and reaction rate constants $(k, \mathrm{~cm} / \mathrm{s})$ by following an increasing trend with increasing temperature. Moreover, it was validated by the correlation coefficient $\left(c_{\text {coee }} \geq\right.$ $0.9794)$, the root mean square error $(R M S E \leq 0.485)$, the mean relative deviation modulus $(E \leq$ $3.290 \%)$, and the activation energy value $\left(E_{a}=19.15 \mathrm{kJmol}^{-1}\right)$. This model could describe the aluminum leaching kinetics from peat clay that suitable with experiment parameters and statistical criteria, by giving useful information for optimization, scaling-up, and design.
\end{abstract}

Keywords: Aluminum, kinetics, leaching, peat clay

\section{INTRODUCTION}

The clay minerals are naturally aluminum silicate that essentially composed of silica, alumina, iron, magnesium and water in varying levels, as well as the other compounds that frequently presented in small quantity (Ajemba and Onukwuli, 2012). While, peat clay located at a depth of about 1.5 to 3.0 meters from the peat soil is known as clay soil which mostly contains a major chemical composition in shape of aluminum oxide, silica oxide, and iron oxide (Mirwan et al., 2018). Aluminum in form of aluminum oxide has a potential as coagulants, adsorbents and catalysts for water and wastewater treatment (Karjalainen et al., 2016). In general, clay has several remarkable advantages such as good acid tolerance, low cost, good mechanical properties, easy solid-liquid separation and excellent reusability (Iannicelli Zubiani et al., 2015).

The readability of aluminum in the aluminum leaching from peat clay materials is currently concentrated on increasing the aluminum content for scientific goals only. Acid leaching is one of the most common chemical modifications applied to peat clay minerals. Previously, the peat clay is activated using a thermal treatment or calcination for increasing the reactivity of dehydration transformation of kaolinite to amorphous metakaolinite and straightforward to leached with acid solution (Brown and Hrishikesan, 1962; Wendt and O'Connor, 1989).

According to Estokova et al. (2015), leaching is the process of dissolving and removing soluble components from a material using solvent media. This process is initial act for the utilization of aluminum from natural resources in obtaining valuable material such as coagulant, adsorbent, and catalysts. The leaching process is the mass transfer process from solid to liquid in which the solute can be leached out based on the solubility, pores, and particle surface. Gertenbach (2002) and
Schwartzberg \& Chao (1982) explained that partition constants and kinetic parameters are related to equilibrium which will be used in the calculation of mathematical models. In the engineering and separation process, mathematical modeling is necessary because it provides quick and inexpensive calculations and minimizes the number of required experiments. Mass transfer mechanisms are very easy to understand with the analysis of model parameters that will be needed for process optimization, simulation, and reactor design.

The shrinking core (SC) model is the most widely used model for the leaching of different constituents from natural mineral materials or hydrometallurgy to acquire metal or other precious materials (Safari et al., 2009; Santos et al., 2010; Xue et al., 2011; Li et al., 2013; Mirwan et al., 2017). In addition to studies on the kinetics of leaching aluminum from metallurgical materials such as clay, peat clay, and water treatment sludge (Cheng et al., 2012; Cheng et al., 2014; Mirwan et al., 2018), to greats of science, only one study has been published on the aluminum leaching kinetics of water treatment sludge, which also used SC model. Previous study (Mirwan et al., 2018) indicated that the aluminum leaching from peat clay is influenced by the acid concentration, particle in small size, and leaching temperature. The increase of aluminum rate in leaching process is followed by the increase of acid concentration, leaching temperature, and particle in the small size. The highest aluminum leaching yield was reached at $90{ }^{\circ} \mathrm{C}$, $+200-325$ mesh, and 4M HCl (Mirwan et al., 2018). A well appropriate model on aluminum leaching peat clay was accomplished; nevertheless, the parameters of model did not have bodily sense. While for industrial scale, leaching kinetics data for optimization process, reactor design, and suitable model is not existed yet.

The major purpose of this research was to investigate the effect of temperature that varied between 30 and $90{ }^{\circ} \mathrm{C}$ on the aluminum 
leaching rate from peat clay and to evolve the leaching kinetics model by depending on temperature parameters.

\section{EXPERIMENTAL}

\section{Materials}

Peat clay from Peat Village, District of Banjar, South Kalimantan and in depths about 3.0 meters from surface of the earth was used. Manually, peat clay was cleaned and dried for 48 hours in direct sunlight. After crushing and grinding, the peat clay was sieved to the size fraction of $0.044-0.210 \mathrm{~mm}$ and calcined for thermal treatment at $700{ }^{\circ} \mathrm{C}$ for $2 \mathrm{~h}$. From Sigma-Aldrich with a purity of $37 \%, 1.18 \mathrm{~g} / \mathrm{mL}$, $\mathrm{HCl}$ was used as the leaching solution. Desired $\mathrm{HCl}$ concentrations were diluted with de-ionized water.

\section{Leaching procedure}

Aluminum leaching was carried out in an atmospheric Iwaki Pyrex two-neck reactor; for the thermometer and for the inlet and/or outlet of the sample periodically (Fig. 1). Magnetic stirrer (300 rpm) with heating indirectly through a water bath was used for mixing reaction. 5 $\mathrm{g}$ of calcined peat clay was added and reacted into $250 \mathrm{~mL}$ of $\mathrm{HCl}$ solution at specific temperature. The solid/liquid ration was kept constant at $0.02 \mathrm{~g} / \mathrm{mL}$. Sample was taken using a syringe at selected time interval and filtered using filter paper for analysis of aluminum content by inductively coupled plasmacluster optical emission spectrometer (ICP-OES) (9060-D Teledyne Leeman Labs. USA). Repetition of each analysis was carried out three times and represented by the average value. The equation of $x=\left(X / X_{0}\right) \times 100$, states the aluminum recovery $(x)$; the total aluminum achieved through the acid leaching process is expressed as $X_{0}$, and the amount of aluminum obtained at different conditions $(\mathrm{mg} / \mathrm{g})$ is expressed by $X$.

In solid-phase amorphous in peat clay, aluminum hydroxide can be leached out by acid due to the fact that aluminum oxide is inert at ambient temperature in acidic condition. Chemical reaction of aluminum oxide with acid was stated as follow: $\mathrm{Al}(\mathrm{OH})_{3(S)}+$ $3 \mathrm{HCl}_{(a q)} \rightarrow \mathrm{AlCl}_{3(a q)}+3 \mathrm{H}_{2} \mathrm{O}$.

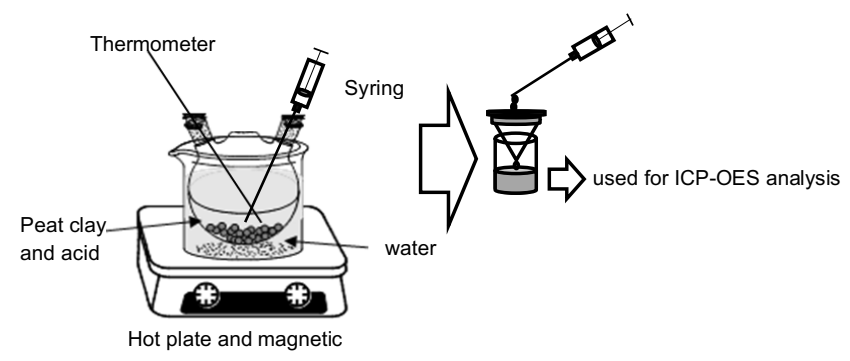

Fig. 1 Leaching process equipment design.

\section{Mathematical modelling of leaching kinetics}

The principle of SC model from the previous paper (Mirwan et al., 2017) explained that firstly the $\mathrm{HCl}$ ions were diffused through film surrounding the surface of peat clay particles. The untreated core surface was continuously penetrated and diffused through the blanket of product layer by the acid ions, and reacted with the aluminum precipitate. Eventually, all aluminum ions in the peat clay particles were diffused out to the surrounding liquid. Furthermore, the SC model assumed that peat clay particles were spherical and their spherical shape could be maintained during reacting completely. Based on Mirwan et al. (2017), the mechanism of aluminum leaching was shown in Fig 2.

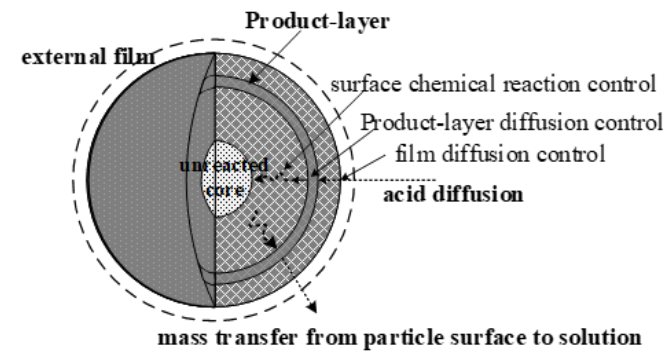

Fig. 2 The mechanism of aluminum leaching of the SC model.
The overall mass balance equation for leaching as following:

$$
\frac{d C_{A L}}{d t}=\frac{k_{c}}{R} \frac{\left(1-\varepsilon_{L}\right)}{\varepsilon_{L}}\left(C_{A(R)}-C_{A L}\right)
$$

where, $C_{A L}$ is concentration in the solvent $\left(\mathrm{kmol} / \mathrm{m}^{3}\right), C_{A(R)}$ is concentration of aluminum leaching $\left(\mathrm{kmol} / \mathrm{m}^{3}\right), k_{c}$ is mass transfer coefficient $(\mathrm{cm} / \mathrm{s}), \varepsilon_{L}$ is void fraction, and $R$ is particle radius $(\mathrm{m})$. The mass transfer rate of solute was related to aluminum concentration in peat clay particle (time variation of the solid phase) and calculated using following equation:

$$
\frac{d q}{d r}=\frac{4 \pi R^{2} k_{c} \rho_{s}}{b \times \text { solid mass }}\left(C_{A(R)}-C_{A L}\right)
$$

where $\bar{q}$ is average value of $q\left(\mathrm{~mol} / \mathrm{m}^{3}\right), b$ is stoichiometric coefficient, $\rho_{s}$ is sludge solid waste density $\left(\mathrm{kg} / \mathrm{m}^{3}\right)$, and $\pi$ is the ratio of a circle's (3.14159). The outer particle diffusion was used and calculated using:

$$
-\frac{d}{d r}\left(-D_{e} 4 \pi r^{2} \frac{d C_{A(R)}}{d r}\right)=0
$$

where, $D_{e}$ is effective diffusivity $\left(\mathrm{m}^{2} / \mathrm{s}\right)$ and $r$ is radial coordinate. The average solute concentration was then calculated using equation:

$$
\frac{\bar{q}}{q_{0}}=\left(\frac{r_{c}}{R}\right)^{3}
$$

where $q_{0}$ is initial solid-phase concentration $\left(\mathrm{mol} / \mathrm{m}^{3}\right)$ and $r_{c}$ is critical radius of core $(\mathrm{m})$. Boundary conditions and initial conditions were measured according to following equations:

$$
\begin{aligned}
& r=r_{c} \rightarrow D_{c} \frac{C_{A(R)}}{d r}=k C_{A(R)} \\
& -D_{c} \frac{C_{A(R)}}{d r}=k_{c}\left(C_{A(R)}-C_{A L}\right) \\
& r_{c}=R \text { and } \bar{q}=q_{0} \text { at } t=0
\end{aligned}
$$

$k$ is reaction rate constant $(\mathrm{cm} / \mathrm{s})$. Fitting the experimental data to Eq.(6) to (8) could obtain the model parameters i.e. $k_{c}, k$, and $D_{e}$. Through the integration of Equation 4, the concentration of aluminum leaching $\left(\mathrm{kmol} / \mathrm{m}^{3}\right)$ could be obtained

$$
C_{A(R)}=\frac{k_{1}}{r}+k_{2}
$$

The substitution of Equation 6 to Equation 9 is could obtained

$$
k_{1}=\frac{k k_{2} r_{c}^{2}}{\left(D_{e}+k r\right)}
$$

where, $k_{1}$ and $k_{2}$ are first and second partition constants $\left(\mathrm{kg} / \mathrm{m}^{3}\right)$. The incorporation of Equations 6, 8, and 9 is yielded the solute mass of the aluminum recovery. The $k_{1}$ and $k_{2}$ variables were obtained from the solution of Equation 7 to obtain concentration of aluminum leaching $\left(\mathrm{kmol} / \mathrm{m}^{3}\right)$ or $C_{A(R)}$.

$$
\begin{gathered}
k_{2}=\frac{k_{c} C_{A L}\left(D_{e}+k r_{c}\right) R^{2}}{D_{c}\left(k r_{c}^{2}+R^{2} r_{c}\right)+k_{c} k\left(r_{c} R^{2}-r_{c}^{2} R\right)} \\
C_{A(R)}=\frac{k_{c} C_{A L} R^{2} r_{c}^{2}}{D_{e}\left(k r_{c}^{2}+R^{2} k_{c}\right)+k_{c} k\left(r_{c} R^{2}-r_{c}^{2} R\right) r} \\
+\frac{k_{c} C_{A L}\left(D_{e}+k r_{c}\right) R^{2}}{D_{e}\left(k r_{c}^{2}+R^{2} k_{c}\right)+k_{c} k\left(r R^{2}-r_{c}^{2} R\right)}
\end{gathered}
$$




\section{Statistical analysis}

The experimental data was used to determine the proposed model parameters through nonlinear regression. The sufficiency of the appropriate model with experimental data would be evaluated by three statistic results, i.e. correlation coefficient $\left(c_{\text {coef }}\right)$, root mean square error (RMSE), and modulus of mean relative deviation $(E)$. A good fit between the model and the data was indicated by $c_{\text {coef }} \rightarrow 1, R M S E \rightarrow$ 0 , and $E<10 \%$ (Mirwan et al., 2017). $c_{c o e f}$, RMSE, and $E$ were computed as:

$$
\begin{aligned}
& c_{\text {coef }}=\sqrt{1-\frac{\sum_{i=1}^{N}\left(C_{p r e d, i}-C_{\text {exp }, i}\right)^{2}}{\sum_{i=1}^{N}\left(C_{\text {exp }, i}-C_{\text {exp }, s r}\right)^{2}}} \\
& R M S E=\sqrt{\frac{1}{N} \cdot \sum_{i=1}^{N}\left(C_{p r d, i}-C_{\text {epp }, i}\right)^{2}}
\end{aligned}
$$

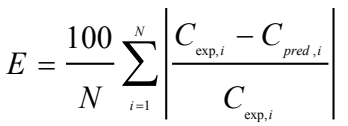

where $C_{\text {pred, } i}$ is predicted aluminum recovery calculated with the model, particle core (\%), $C_{\text {exp,i }}$ is experimental value of aluminum recovery, particle core (\%), $C_{\text {exp,sr }}$ is experimental value of aluminum recovery, solid phase (\%), and $N$ is number of experimental points.

\section{RESULTS AND DISCUSSION}

Fig. 3 illustrates that the total aluminum rate in the leaching yield evaluated at a leaching temperature of $30,50,70$ and $90{ }^{\circ} \mathrm{C}$. The increasing leaching temperature was followed by the increasing leaching yield; aluminum recovery value was $91.267 \%$ at $90{ }^{\circ} \mathrm{C}$ and $60 \mathrm{~min}$ of leaching. The form of leaching curve was equal to the form of curve informed by Mirwan et al., (2017) for aluminum leaching from water treatment sludge. Furthermore, aluminum leaching from peat clay was more sensitive to temperature at $90{ }^{\circ} \mathrm{C}$, which indicates that the diffusion process is likely to continue. The layer is still slowly formed on the surface of the particle and accelerated the acid to reach the reactive zone at leaching temperature of $90{ }^{\circ} \mathrm{C}$ and above. This finding was contradicted to the statement of Cui et al., (2015) that leaching aluminum is less sensitive to temperatures between $90^{\circ} \mathrm{C}$ and $106^{\circ} \mathrm{C}$.

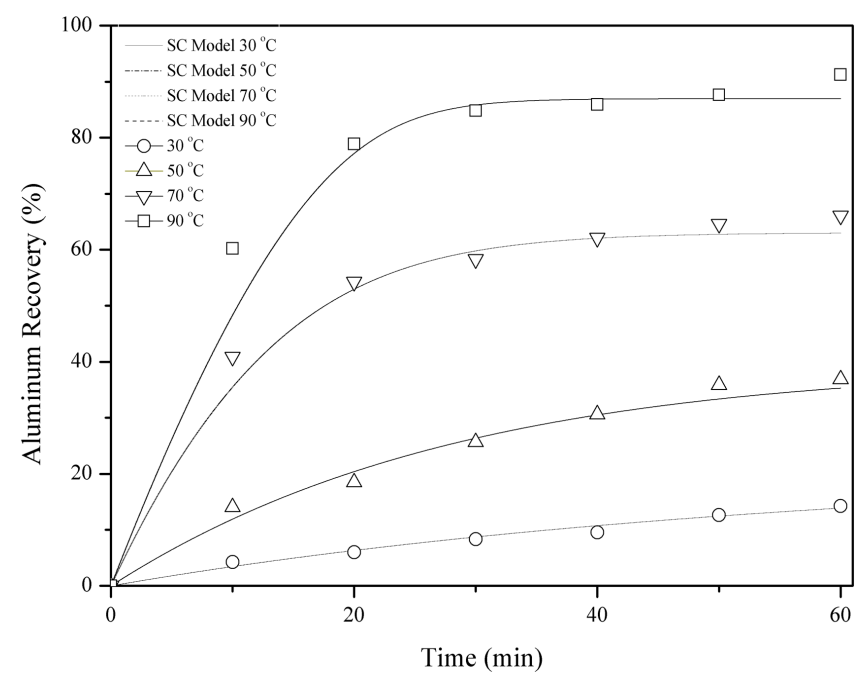

Fig. 3 Aluminum recovery from experimental data and model curves.

The experimental data has been tested and appropriated with Eq. (12) through minimizing the root mean square distinction. The adjusting model parameters were showed: the temperature-dependent reaction rate constant, mass transfer coefficient, and effective diffusivity, which the values were written in Table 1 along with the statistic results. The radius of the $R$ particle and the ratio of solid to solvent were fixed at $0.0295 \mathrm{~cm}(262.5 \mathrm{mesh})$ and $0.02 \mathrm{~g} / \mathrm{mL}$, respectively. The correlation coefficient $\left(c_{\text {coef }} \geq 0.9602\right)$ and $R M S E$ values $(\leq 0.854)$ were comparatively low, while $E$ values were under $3.2903 \%$ for every temperature. The model was is appropriate to prophesy the aluminum leaching kinetics from peat clay.

The connections of the mass transfer coefficient, the reaction rate constants, the diffusion coefficient and the leaching temperature that is numerically used the Arrhenius equation in the form of a logarithm could be explained by the activation energy (Mirwan et al., 2017):

$\ln k=\ln A-\frac{E_{a}}{R T}$

where the pre-exponential factor is symbolized by A, the activation energy $(\mathrm{J} / \mathrm{mol})$ is $E_{a}$, the global gas constant $(8.314 \mathrm{~J} / \mathrm{K} \mathrm{mol})$ is $R$, and the absolute temperature $(\mathrm{K})$ is $T$. Based on the calculation of the graph slope of $\ln \mathrm{k}$ to the inverse absolute temperature, activation energy value can be obtained. The $k$ value is inversely proportional to the temperature. Fig. 4 exhibits that the activation energy result was 19.15 $\mathrm{kJ} / \mathrm{mol}$.

The RMSE criterion follow the expected trend of increasing as the temperature is increased by assessing the minimized effective diffusion coefficient.

Table 1 Fitting model parameters and statistical criteria at distinct leaching temperatures $(T)$.

\begin{tabular}{ccccc}
\hline $\boldsymbol{T}\left({ }^{\circ} \mathbf{C}\right)$ & $\mathbf{3 0}$ & $\mathbf{5 0}$ & $\mathbf{7 0}$ & $\mathbf{9 0}$ \\
\hline$k(\mathrm{~cm} / \mathrm{s})$ & 12.4 & 18.5 & 30.8 & 42.2 \\
$k_{c}(\mathrm{~cm} / \mathrm{s})$ & 0.0003 & 0.0014 & 0.0050 & 0.0063 \\
$D_{e .10^{-5}\left(\mathrm{~cm}^{2} / \mathrm{s}\right)}$ & 0.21 & 1.69 & 10.38 & 25.08 \\
$C_{\text {coef }}$ & 0.9602 & 0.9860 & 0.9906 & 0.9794 \\
$R M S E$ & 0.0330 & 0.0863 & 0.2211 & 0.4854 \\
$E(\%)$ & 3.1693 & 2.5095 & 2.2074 & 3.2903 \\
\hline
\end{tabular}

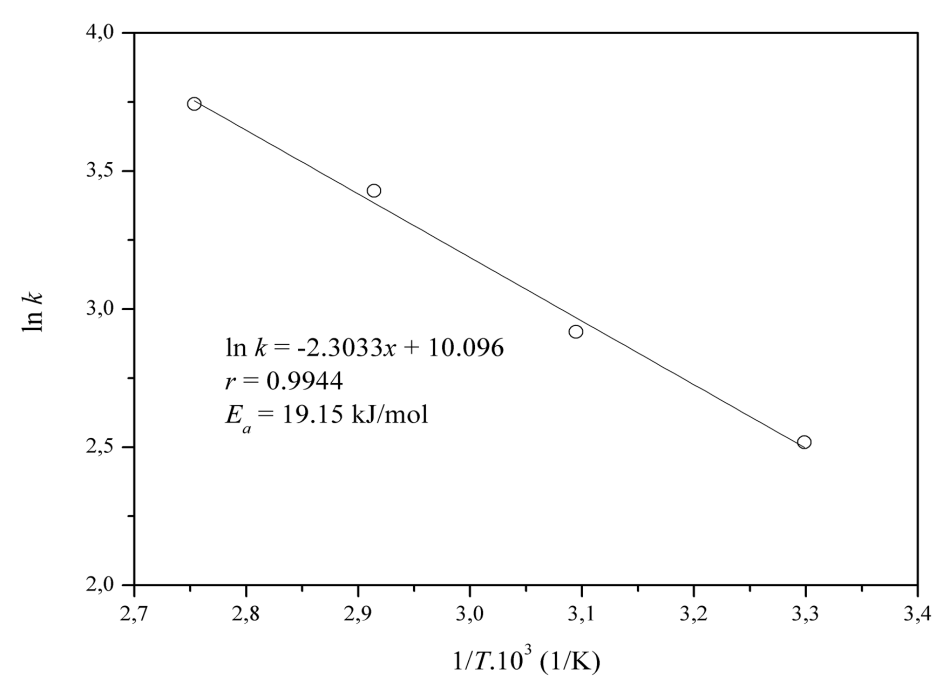

Fig. 4 Arrhenius graph: $k$ is the reaction rate constant, $\mathrm{cm} / \mathrm{s}$ and $\mathrm{T}$ is the absolute leaching temperature, $\mathrm{K}$.

\section{CONCLUSION}

The results in this research depicted that the maximum aluminum leaching recovery from peat clay was occurred on $4 \mathrm{M} \mathrm{HCl}$ and at temperature of $90^{\circ} \mathrm{C}$. The offered model was appropriate to depict the aluminum leaching kinetics from peat clay in conformation with the research conditions, which was verified by statistical criteria. The physical purpose of model kinetic parameter provides good concept of 
mass transfer phenomena through the batch aluminum leaching from peat clay. Thus, valuable information needed for simulation, optimization, scale-up and leaching process design can be obtained from this study.

\section{ACKNOWLEDGEMENT}

The authors would like to convey appreciation to the Directorate General of Higher Education, Ministry of Education and Culture Republic of Indonesia (No. 23428/A4.2/2014) for financially supporting this work.

\section{REFERENCES}

Ajemba, R.O., Onukwuli, O.D., 2012. Application of the shrinking core model to the analysis of alumina leaching from ukpor clay using nitric acid. International Journal of Engineering Research \& Technology. 1, 3, 1-13.

Brown, W.H., Hrishikesan, K.G., 1966. Process for the production of alumina. United States Patent Online, No. 3, 240, 562.

Cheng, W.-P., Fu, C.-H., Chen, P.-H., Yu, R.-F., 2012. Dynamics of aluminum leaching from water purification sludge. Journal of Hazardous Materials. 217-218, 149-155.

Cheng, W.-P., Fu, C.-H., Chen, P.-H., Yu, R.-F., 2014. Factors affecting aluminum dissolve from acidified water purification sludge. International Journal of Chemical, Molecular, Nuclear, Material and Metallurgical Engineering. 8, 8, 878-881.

Cui, L., Guo, Y., Wang, X., Du, Z., Cheng, F., 2015. Dissolution kinetics of aluminum and iron from coal mining waste by hydrochloric acid. Chinese Journal of Chemical Engineering. 23, 590-596.

Estokova, A., Oravec, J., Kovalcikova, M., 2015. Environmental impact assessment of the concrete composites in terms of the selected toxic metals leaching. Chemical Engineering Transactions. 43, 1915-1920.

Gertenbach, D., 2002. Solid-liquid extraction technologies for manufacturing nutraceuticals. In J. Shi, G. Mazza, \& M. Le Maguer (Eds.), Functional foods: Biochemical and processing aspects. Boca Raton FL: CRC Press. 331 -366 .

Iannicelli Zubiani, E.M.I., Cristiani, C., Dotelli, G., Stampino, P.G., Pelosato, R., 2015. Recovery of rare earths and precious metals from waste electrical and electronic equipment by acid leaching and immobilized chelating agents. Chemical Engineering Transactions. 43, 2413-2418.

Karjalainen, S.M., Ronkanen, A.-K., Heikkinen, K., Kløve, B., 2016. Long-term accumulation and retention of al, fe and $\mathrm{p}$ in peat soils of northern treatment wetlands. Ecological Engineering. 93, 91-103.

Li, M., Zhang, X., Liu, Z., Hu, Y., Wang, M., Liu, J., Yang, J., 2013. Kinetics of leaching fluoride from mixed rare earth concentrate with hydrochloric acid and aluminum chloride. Hydrometallurgy. 140, 71-76.

Mirwan, A., Susianto, S., Altway, A., Handogo, R., 2017. A modified shrinking core model for leaching of aluminum from sludge solid waste of drinking water treatment. International Journal of Technology. 8,1, 19-26.

Mirwan, A., Susianto, S., Altway, A., Handogo, R., 2018. Kinetic model for identifying the rate controlling step of the aluminum leaching from peat clay. Jurnal Teknologi. 80, 2, 37-44.

Safari, V., Arzpeyma, G., Rashchi, F., Mostoufi, N., 2009. A shrinking particle - shrinking core model for leaching of a zinc ore containing silica. International Journal of Mineral Processing. 93, 1, 79-83.

Santos, F. M. F., Pina, P. S., Porcaro, R., Oliveira, V. A., Silva, C. A., Leao, V.A., 2010. The kinetics of zinc silicate leaching in sodium hydroxide. Hydrometallurgy. 102, 43-49.

Schwartzberg, H. G., Chao, R. Y., 1982. Solute diffusivities in leaching processes. Food Technology. 73-86.

Wendt, H., O'Connor, D. J., 1989. Alumina extraction from non bauxitic materials, Aluminium-Verlag GmbH, Düsseldorf. 1988. 370 Seiten, Preis: DM 160, Berichte Bunsenges. International journal of research in physical chemistry and chemical physics. 93, 5, 639-639.

Xue, B., Sho-hua, Y., Wen-yuan, W., 2011. Leaching kinetics of bastnaesite concentrate in $\mathrm{HCl}$ solution. Transactions of Nonferrous Metals Society of China. 21, 2306-2310. 